\title{
Designing the Future in Higher Education
}

\author{
Libby V. Morris ${ }^{1}$
}

Published online: 3 August 2018

(C) Springer Nature B.V. 2018

A large number of institutions struggle to bring about higher levels of student persistence, retention, and graduation in the context of ongoing public concerns about the cost and value of higher education. Concomitantly, it is difficult to plan for the future under the intense pressures created by public scrutiny, tight budgets, and competition for students and resources. Yet, rapid changes in higher education delivery mechanisms, student demographics, and workforce needs demand attention. It is in this context that the Georgia Institute of Technology (Ga Tech) established a Commission on Creating the Next in Education (CNE). Provost Rafael Bras convened and charged the group with envisioning and defining "...the technological research university of the $21^{\text {st }}$ century." The Commission recognized that leading institutions will make detailed plans for the future and will incorporate both the traditional linear, fixed-time models prevalent in postsecondary education with new pedagogical paradigms to engage students and graduates for a lifetime. This approach is captured as the Georgia Tech Commitment to a Lifetime Education.

I was particularly interested in the CNE 2018 report, Deliberate Innovation, Lifetime Education, because Georgia Tech consistently ranks as a top 10 public institution, recognized around the world for excellence in engineering as well other academic fields. Admissions are competitive; graduation rates are high; and graduates rapidly move into successful careers. Nevertheless, Ga Tech saw dramatic change on the horizon and moved to respond. The 50+ member commission expended hundreds of hours across three years and countless meetings across multiple subgroups to complete their work. I was curious about how a select planning group at a leading U.S. research institution would think about the future of education? Where would the group and the institution see the opportunities and challenges in defining the future?

The Commission's charge was to address Ga Tech's current educational practices and methods, to benchmark best practices, and to make recommendations about serving learners in the future. In anticipation of the growing diversity of students, the report describes a model that goes beyond college as a place for a specific age-group focused on degrees. That model becomes a platform for serving diverse students, across a lifetime and around the globe. The report is quick to state that the traditional residential experience will remain the core of the GA

Libby V. Morris

lvmorris@uga.edu 
Tech mission, while at the same time the institution designs new tools and approaches to serve increasing numbers of non-traditional, socially, economically and ethnically diverse students.

The report's central thrust is to design responsive educational opportunities for engagement across a lifetime. Recurring themes include educating the whole person, education outside the demographic sweet spot, and personalized education. Four key actions were identified as important to achieve the shift in focus.

- Eliminate barriers between pre-college and college.

- Reinvent the physical presence of college to serve students worldwide.

- Enable continuous learning with flexible pathways and new credentials.

- Provide advising and coaching networks that will serve GA Tech students for life.

The report identifies five initiatives that are important to inform the next steps for achieving this vision for the future, the Georgia Tech Commitment. Initiative one, whole person education, addresses the importance of experiential learning, globalization at home, professional development of graduate students that fuses traditional research-oriented training with whole person education, and a whole person curriculum that emphasizes interpersonal and intrapersonal competencies along with cognitive accomplishments. Ga Tech will have many models to explore as liberal arts institutions have long held this competency among their top priorities. Bringing whole person education to an intensive research institution will not be without challenges; but for a top 10 U.S. public research institution to even have this as a goal is laudable.

Initiative two calls for the development of new products and services that will allow Ga Tech students to customize their learning experiences. The report describes micro-credentials, minimester classes, and the use of blockchain technology to create a new decentralized transcript. Navigating accreditation issues and the long-standing Carnegie unit will not be without challenges. Initiative three expands on new advising models for the future that are personalized, technology-driven, and underpinned by boards of directors worldwide for Georgia Tech learners.

Initiative four emerges directly from GA Tech's strength, that is, designing and implementing artificial intelligence to achieve many of its futuristic objectives. The initiative envisions the development of mastery learning and adaptive learning platforms for customized delivery of educational materials and personalized learning experiences. Initiative five aims to take the Ga Tech experience beyond the physical presence of a single campus to allow students and faculty to work together in a distributed worldwide model through the concepts of the Georgia Tech Atrium ${ }^{\mathrm{TM}}$ and the Living Library for Learning (L3). The atriums can be distributed near GA Tech learners; and each atrium, whether located in a corporate location or mall, can be designed to suit the ongoing needs for cost-effective, quality education. The L3 is conceived of as "loaning people, not books." I cannot begin to describe the detail associated with each initiative, and even one would be a challenge a plenty!

GA Tech is planning to treat each initiative as a research and design project to plan for the future. In case you have not picked up the theme, GA Tech is not only in the business of educating engineers and other scientists with specific technical skills; it is moving with intention into the business of education across the globe and for students for a lifetime. I encourage you to read this report in its entirety, and it is available at the Ga Tech web site (http://www.provost.gatech.edu/commission-creating-next-education). How is your institution planning for the future? How will it keep its traditions intact while planning for inevitable change? These are questions we should all be asking ourselves. 